\title{
The Glucocorticoid Receptor Cooperates With the Erythropoietin Receptor and c-Kit to Enhance and Sustain Proliferation of Erythroid Progenitors In Vitro
}

\author{
By Marieke von Lindern, Wolfgang Zauner, Georg Mellitzer, Peter Steinlein, Gerhard Fritsch, Klaus Huber, \\ Bob Löwenberg, and Hartmut Beug
}

\begin{abstract}
Although erythropoietin (Epo) is essential for the production of mature red blood cells, the cooperation with other factors is required for a proper balance between progenitor proliferation and differentiation. In avian erythroid progenitors, steroid hormones cooperate with tyrosine kinase receptors to induce renewal of enythroid progenitors. We examined the role of corticosteroids in the in vitro expansion of primary human erythroid cells in liquid cultures and colony assays. Dexamethasone (Dex), a synthetic glucocorticoid hormone, cooperated with Epo and stem cell factor to induce erythroid progenitors to undergo 15 to 22 cell divisions, corresponding
\end{abstract}

$\mathbf{T}$

HE DEVELOPMENT OF mature, peripheral blood cells from pluripotent stem cells in the bone marrow is a complex process in which lineage commitment, proliferation, differentiation, and cell survival have to be perfectly balanced. Pluripotent stem cells are maintained via self renewal (ie, proliferation without detectable entry of a differentiation pathway), while, in addition, they are able to give rise to multipotent and committed progenitors. The latter progenitors differentiate along a specific cell lineage(s) in a process thought to occur according to a fixed program, dictating both the remaining number of cell divisions and the time of entry into terminal differentiation. ${ }^{1,2}$ Because of genetic changes, the regulation of commitment and differentiation is disregulated in leukemia.

Leukemic transformation of avian erythroid progenitors by the oncoproteins v-ErbA and v-ErbB, present in avian erythroblastosis virus, appeared to be based on a mechanism that is latently present in normal cells. ${ }^{3}$ Normal avian erythroid progenitors express tyrosine kinase receptors related to $\mathrm{v}$-ErbB (ie, c-ErbB and c-Kit, using transforming growth factor $\alpha$ $[\mathrm{TGF} \alpha]$ and avian stem cell factor [SCF] as ligands) and nuclear hormone receptors with a function similar to v-ErbA (estrogen receptor and glucocorticoid receptor). ${ }^{3}$ Simultaneous stimulation of these two receptor types in normal bone marrow cells results in the outgrowth of committed erythroid progenitors that

From the Institute of Hematology, Erasmus University, Rotterdam, The Netherlands; the Institute of Molecular Pathology, Vienna, Austria; the Children's Cancer Research Institute, St. Anna Kinderspital, Vienna, Austria; and the Department of Laboratory Medicine, Donauspital SMZ-Ost, Vienna, Austria.

Submitted December 2, 1998; accepted March 22, 1999.

Supported by grants from the Forschungsförderungsfund für die Gewerbliche Wirtschaft (FFF3/10628), the Dutch Cancer Society (EUR 95-1021), and the European Community (Biomed 2-PL951355).

Address reprint requests to Marieke von Lindern, PhD, Institute of Hematology, Erasmus University, p/o Box 1738, 3000 DR Rotterdam, The Netherlands; e-mail: vonlindern@ hema.fgg.eur.nl.

The publication costs of this article were defrayed in part by page charge payment. This article must therefore be hereby marked "advertisement" in accordance with 18 U.S.C. section 1734 solely to indicate this fact.

(1) 1999 by The American Society of Hematology.

0006-4971/99/9402-0040\$3.00/0 to a $10^{5}$ - to $10^{6}$-fold amplification of erythroid cells. Dex acted directly on erythroid progenitors and maintained the colonyforming capacity of the progenitor cells expanded in liquid cultures. The hormone delayed terminal differentiation into enythrocytes, which was assayed by morphology, hemoglobin accumulation, and the expression of genes characteristic for immature cells. Sustained proliferation of erythroid progenitors could be induced equally well from purified erythroid burst-forming units (BFU-E), from CD34+ blast cells, and from bone marrow depleted from $\mathrm{CD} 34^{+}$cells.

(1) 1999 by The American Society of Hematology.

resemble leukemic cells transformed by v-ErbA and v-ErbB as regards their abilities to proliferate without differentiation for 25 to 30 generations. ${ }^{4-8}$

This progress in identifying the players that regulate the balance between proliferation and differentiation in normal avian erythropoiesis prompted us to study whether similar mechanisms operate in human erythropoiesis. If a similar synergism between tyrosine kinase receptors and steroid hormones would apply to human erythropoiesis, it may be possible to establish mass cultures of human erythroid progenitors through the addition of recombinant factors and hormones that would selectively provoke proliferation and yield cell numbers large enough to perform biochemical and molecular studies.

In mammals, erythropoietin (Epo) and SCF were shown to be crucial factors in erythropoiesis. Mice with a homozygous disruption of the gene encoding Epo or the Epo-receptor (EpoR) die at day 13.5 of gestation due to a lack of erythrocytes. ${ }^{9}$ Erythroid burst-forming units (BFU-E) and erythroid colonyforming units (CFU-E) can be isolated from the fetal liver of these mice, but cells lacking the EpoR cannot mature to erythrocytes. ${ }^{9,10}$ Mice that lack SCF or c-Kit, its receptor, suffer from severe anemia. ${ }^{11,12} \mathrm{c}$-Kit is expressed on the cell surface of the earliest progenitor up to the stage of the basophilic erythroblast. ${ }^{13}$ In the presence of SCF, erythroid progenitors undergo an increased number of cell divisions before they develop into mature erythrocytes. ${ }^{14,15}$

The role of steroids in mammalian erythropoiesis has remained elusive. In macrophages and lymphocytes, glucocorticoids induce apoptosis due to inhibition of AP1 and $\mathrm{NF \kappa B}$ transcription complexes. ${ }^{16}$ However, glucocorticoids were shown to increase the number of erythroid colonies grown in vitro from normal bone marrow, ${ }^{17-19}$ and treatment of nonanemic patients with the synthetic glucocorticoid receptor (GR) ligand prednisone has been suggested to enhance erythropoiesis. ${ }^{20}$ Thus, the GR may have a stimulatory role in mammalian erythropoiesis similar to what was found in avian erythroid progenitors.

In this report, we demonstrate that the addition of the GR ligand dexamethasone (Dex) to Epo and SCF allowed the establishment of mass cultures of normal erythroid progenitors from mononuclear cells of human umbilical cord blood, bone marrow, and peripheral blood. Erythroid cells in these mass 
cultures underwent 15 to 20 cell divisions. Cultures of purified BFU-E, as well as $\mathrm{CD} 34^{+}$and even $\mathrm{CD} 34^{-}$cells could be expanded up to $10^{6}$-fold. Morphologically, $95 \%$ of the cells in the culture appeared as proerythroblasts, which could be induced to terminal erythroid differentiation upon removal of SCF and Dex. Single-cell cloning experiments suggested that Dex acts directly on human erythroid progenitors, maintaining their colony-forming capacity and delaying their differentiation.

\section{MATERIALS AND METHODS}

Cells and cell culture. Neonatal cord blood, bone marrow, or buffy coat from peripheral blood was obtained from healthy volunteers after informed consent was received. Mononuclear cells were purified by centrifugation over a Ficoll gradient and seeded in CFU-E medium as described, ${ }^{5,6}$ with minor modifications: conalbumin was replaced by human transferrin (iron-loaded; Sigma, St Louis, MO), chicken serum was omitted and only fetal calf serum (FCS; $12 \%$; GIBCO, Grand Island, NY) was used. Unless mentioned otherwise, we used $0.5 \mathrm{U} / \mathrm{mL}$ recombinant human Epo (a kind gift from Janssen-Cilag, Tilburg, The Netherlands), $100 \mathrm{ng} / \mathrm{mL}$ recombinant human SCF (a kind gift from Amgen [Thousand Oaks, CA] or purchased from R\&D [Minneapolis, $\mathrm{MN}]$ ), $40 \mathrm{ng} / \mathrm{mL}$ recombinant human insulin-like growth factor-I (IGF-I; R\&D), $1 \mathrm{U} / \mathrm{mL}$ human insulin (Actrapid; $40 \mathrm{IU} / \mathrm{mL}$; BayerLeverkusen, Leverkusen, Germany), $5 \times 10^{-7} \mathrm{~mol} / \mathrm{L}$ Dex (Sigma), and $5 \times 10^{-7} \mathrm{~mol} / \mathrm{L}$ Dex-antagonist ZK112,993 (a kind gift from Schering, Madison, NJ); obtained through Dr E. Müllner, Biocenter, Vienna, Austria). In initial experiments, $\mathrm{CD} 34^{+}$cells were purified from cord blood on CellPro columns. For the separation of $\mathrm{CD} 34^{+}$cells from bone marrow, Minimacs columns (Miltenyi Biotec, Bergisch Gladbach, Germany) were used. Total mononuclear cells were initially plated at a density of $10 \times 10^{6}$ cells $/ \mathrm{mL}$. During the first 5 days of culture, cell density was reduced to 1 to $2 \times 10^{6} / \mathrm{mL}$. Small mature cells and apoptotic cells were removed once or twice during the first week of the culture by centrifugation through Percoll step-gradients (density, 1.075 $\mathrm{g} / \mathrm{mL}$; Pharmacia, Uppsala, Sweden). Such a purification was always performed when cultures were started from mononuclear cells derived from buffy coat or cord blood; they could be omitted for bone marrow cultures. Cells were kept at 1 to $2 \times 10^{6}$ through daily dilutions or medium changes with fresh medium containing factors. Cells were counted on an electronic cell counter (CASY-1; Schärfe-System, Reutlingen, Germany).

Fluorescence-activated cell sorting (FACS) analysis. Cells were stained using directly labeled antibodies against human cell surface markers (DAKO [Vienna, Austria] and Serotec [Vienna, Austria]) according to the manufacturer's directions. Analysis was performed using a FACScan (Becton Dickinson, San Jose, CA). Propidium iodide-positive cells were excluded from analysis. To sort BFU-E and blast cells, $100 \times 10^{6}$ frozen mononuclear bone marrow cells were thawed and $\mathrm{CD}_{4}{ }^{+}$cells were purified using a MACS CD34 isolation kit (Miltenyi Biotec) according to the guidelines of the supplier. The CD34- fraction was labeled with CD34-Texas Red (TR), and the $\mathrm{CD}_{4}{ }^{+}$fraction was labeled with CD34-TR, CD38-phycoerythrin (PE), and CD71-fluorescein isothiocyanate (FITC) (Becton Dickinson) in one incubation. Cells were washed and resuspended in phosphate-buffered saline (PBS) plus $1 \%$ bovine serum albumin (BSA). Cells were sorted using a FACS-Vantage (Becton Dickinson). After sorting, cell samples were counted, centrifuged on slides, and seeded in human CFU-E medium with factors as described. The initial cell numbers in Fig 6 are recalculated to the total number of cells obtained after sorting.

Determination of hemoglobin accumulation and cell morphology. To determine hemoglobin accumulation, $3 \times 50 \mu \mathrm{L}$ aliquots of the cultures were removed and processed for photometric determination of hemoglobin. ${ }^{21}$ To analyze cell morphology, cells were cytocentrifuged onto slides and stained with histological dyes and neutral benzidine for hemoglobin. ${ }^{22}$ Images were taken using a CCD camera (Photometrics, Tucson, AZ) and a blue filter $(480 \mathrm{~nm})$, so that mature cells (stained yellow to brownish) appear darkly stained. Images were processed with Adobe Photoshop (Adobe Systems Inc, San Jose, CA).

Colony assays. To determine the number of colony-forming cells and their expansion potential, Ficoll-purified bone marrow cells were cultured in CFU-E medium and subsequently seeded at the indicated cell numbers per well in 96-well plates, using CFU-E medium complemented with $1 \mathrm{mg} / \mathrm{mL}$ fibrinogen and $0.1 \mathrm{U} / \mathrm{mL}$ thrombin immediately before aliquoting $50 \mu \mathrm{L}$ of cell suspension per well. After coagulation, another $50 \mu \mathrm{L}$ of medium was added containing combinations of factors at double the concentrations indicated above. Every second day, the medium above the clot was replaced by fresh medium with factors. To determine hemoglobinization of the colonies, $10 \mu \mathrm{L}$ acid benzidine staining solution (a freshly prepared mix of $150 \mu \mathrm{L} 10 \%$ acetic acid, $20 \mu \mathrm{L} 3 \%$ free benzidine base in acetic acid, and $10 \mu \mathrm{L} \mathrm{30 \%}$ $\mathrm{H}_{2} \mathrm{O}_{2}$ ) was added to the medium above the clots.

Northern blot. RNA was isolated from erythroid progenitor cells using the method of Chomczynski and $\mathrm{Sacchi}^{23}$ with minor modifications. Cells were lysed in GITC buffer and NaAc, pH4.0, was added to $25 \mathrm{mmol} / \mathrm{L}$. The solution was extracted with $\mathrm{H}_{2} \mathrm{O}$-saturated phenol plus chloroform and isoamylalcohol. RNA was precipitated with isopropa-

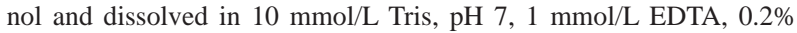
sodium dodecyl sulfate (SDS). Proteinase K was added to $200 \mu \mathrm{g} / \mathrm{mL}$ for 30 minutes at $37^{\circ} \mathrm{C}$. RNA was extracted with phenol:chloroform: isoamylalcohol (25:24:1) pH 7 and precipitated with ethanol. Ten to 20 $\mu \mathrm{g}$ of RNA was run on a formaldehyde-containing agarose gel and transferred to nylon filters (Gene Screen; Gene Vest Inc, Toronto, Canada) using conventional procedures. ${ }^{24}$ Probes used were the entire ORF of human GATA-1, c-myb, c-Kit, or RBTN2/TTG-2.

Phosphotyrosine blot. Cultured cells were washed once with PBS and incubated in medium without growth factors for 12 hours. Cells were washed once with PBS, suspended in medium, and treated 10 minutes at $37^{\circ} \mathrm{C}$ with either $10 \mathrm{U} / \mathrm{mL}$ rhEpo, $1 \mu \mathrm{g} / \mathrm{mL}$ SCF, $400 \mathrm{ng} / \mathrm{mL}$ IGF-I, $100 \mathrm{ng} / \mathrm{mL}$ interleukin-3 (IL-3), $100 \mathrm{ng} / \mathrm{mL}$ granulocytemacrophage colony-stimulating factor (GM-CSF), or $100 \mathrm{ng} / \mathrm{mL}$ insulin. Cells $\left(1 \times 10^{6}\right)$ were lysed in $20 \mu \mathrm{L}$ lysis buffer $(1 \%$ Triton X-100, $50 \mathrm{mmol} / \mathrm{L}$ Tris- $\mathrm{HCl}, \mathrm{pH} 8.0,100 \mathrm{mmol} / \mathrm{L} \mathrm{NaCl}, 1 \mathrm{mmol} / \mathrm{L}$ sodium orthovanadate, $10 \mu \mathrm{g} / \mathrm{mL}$ aprotinin, and $2 \mu \mathrm{g} / \mathrm{mL}$ leupeptin). Cell lysates were cleared by centrifugation for 15 minutes at $15,000 \mathrm{rpm}$ before use. Lysates derived from $5 \times 10^{5}$ cells were run on a $8 \%$ SDSpolyacrylamide gel electrophoresis (SDS-PAGE) and transferred to nitrocellulose membranes (DuPont, Wilmington, DE). The Western blot was probed with the antiphosphotyrosine antibody 4G10 (Upstate Biotechnology, Lake Placid, NY).

\section{RESULTS}

Sustained proliferation of immature human erythroid progenitors. CD34-selected cells or the total fraction of mononuclear cells derived from human cord blood were seeded in CFU-E medium supplemented with Epo, SCF, TGF $\alpha$, estradiol, and Dex. After a lag-phase of 6 days, cell numbers started to increase, with a doubling time of 20 to 24 hours, resulting in a $10^{5}$-fold increase over a 14-day period (Fig 1A). Cell samples were taken from the cultures at subsequent days, and cytological analysis showed typical erythroblasts at various stages of maturation (Fig 1B). After 18 days of culture, both the growth rate and the fraction of cells with a proerythroblast morphology decreased, whereas the number of partially mature erythroid cells increased (Fig 1B, panels 2 and 3). When cells were harvested from the culture, separated by Percoll, and reseeded in secondary cultures, the growth rate of the cultures was 
B

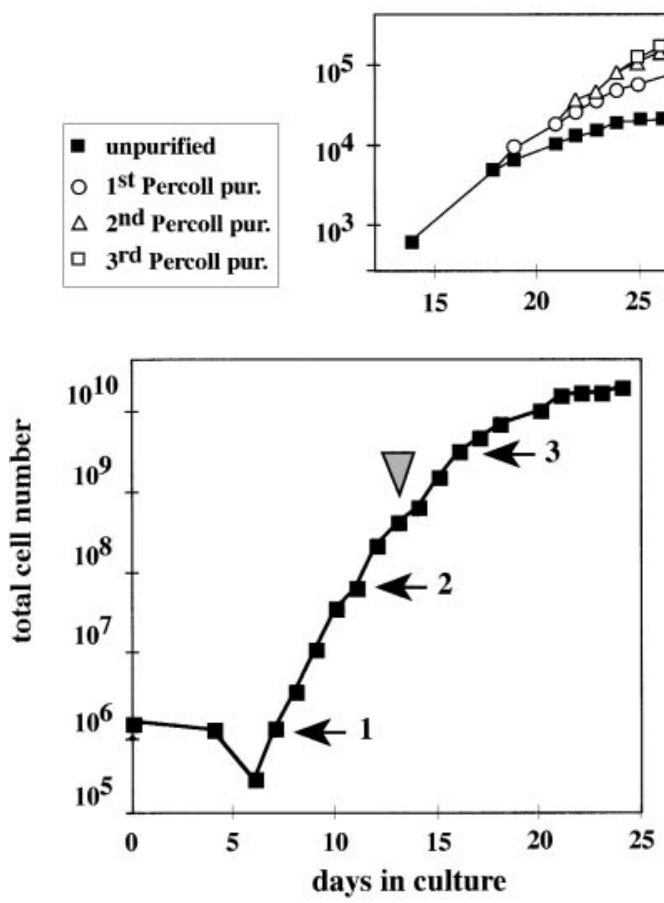

C

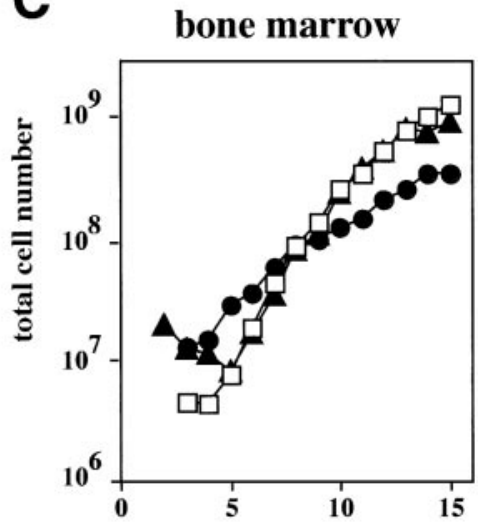

2
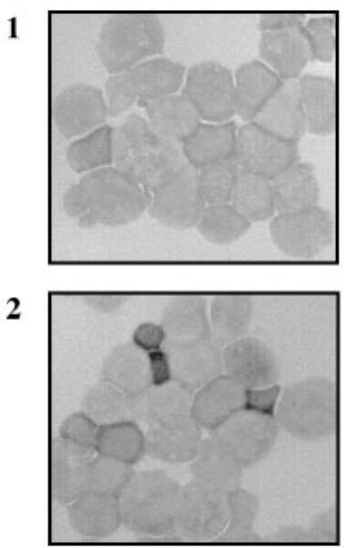

3

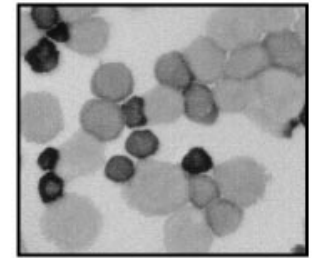

Fig 1. Outgrowth of erythroid progenitors from neonatal cord blood, human bone marrow, or peripheral blood. (A) CD34+ cells isolated from neonatal cord blood were cultured in CFU-E medium complemented with Epo, SCF, IGF-I, and Dex (lower part). Cell density was kept at 1.5 to $3 \times$ $10^{6} \mathrm{cells} / \mathrm{mL}$ and total cell numbers were enumerated at the times indicated. At day 14 (arrowhead), immature low-density cells were purified from the mass culture using Percoll $1.072 \mathrm{~g} / \mathrm{mL}$ and reseeded (top part). This procedure was repeated several times. (B) At day 8 (1), day 12 (2), and day 17 (3) after initiating the culture, cells were cytocentrifuged onto slides and stained with histochemical dyes plus a specific stain for hemoglobin that makes hemoglobinized cells appear dark in this figure. ${ }^{22}$ Numbers of panels correspond to numbered arrows in (A), indicating the time of aliquot removal. (C and D) Ficoll-purified cells from bone marrow ( 3 healthy donors) or from peripheral blood (5 untreated, healthy donors) were cultivated as described in the legend to (A) and cumulative cell numbers were calculated. In case of the peripheral blood-derived cells, apoptotic cells and lymphocytes were removed by centrifugation through Percoll $1.072 \mathrm{~g} / \mathrm{mL}$ at days 4 and 6 of culture.

reestablished using the low-density cell fraction containing immature erythroblasts. Rapid growth could be repetitively restored by successive rounds of purification (Fig 1A, top panel). This indicated that immature progenitors recoverable from the culture had retained the capacity to proliferate (a $10^{6}$-fold expansion equivalent to $\sim 20$ population doublings).

Cultures of human bone marrow or mononuclear cells derived from peripheral blood showed very similar expansion kinetics under the same culture conditions (Fig 1C and D). To determine more accurately the in vitro life span of human erythroid progenitors proliferating in these cultures, mononuclear cells from cord blood were seeded into the above medium under limiting dilution conditions. ${ }^{7,25}$ Cells from wells containing one single colony only were expanded until extinction. During propagation, cell numbers were counted and total cell numbers were enumerated. From more than $80 \%$ of these single colonies between $1 \times 10^{5}$ and $4 \times 10^{6}$ cells were generated, which is equivalent to an average amplification of 16 to 22 generations.
Characterization of the cells grown in cultures supplemented with Epo, SCF, and Dex. FACS analysis of the cells grown in cultures supplemented with Epo, SCF, and Dex showed that most of the cells expressed an immature phenotype (80\% to $95 \% \mathrm{CD} 1^{+}$and $50 \%$ to $80 \% \mathrm{CD} 117^{+}$cells). Approximately $20 \%$ of the cells were maturing erythroid cells $\left(\mathrm{CD}^{+} 6^{+}\right.$and $\mathrm{GPA}^{+}$) and $5 \%$ to $7 \%$ of the cells were of the myeloid or lymphoid lineage (Table 1). Cells lacked CD34 expression, even when stained at only 5 days of culture (data not shown). In addition, cells from several independent cultures were tested in colony assays. Cells taken from 13- or 15-day-old cultures of cord blood formed predominantly erythroid bursts and only a very small number of myeloid colonies (Table 2). These data indicate that the expansion of cultures obtained from mononuclear cells of neonatal cord blood or bone marrow in medium supplemented with Epo, SCF, and Dex is mainly the result of proliferation of erythroid cells.

Finally, we examined whether the cultured cells were responsive to distinct factors in short-term proliferation assays (incor- 
Table 1. FACS Analysis of Cultures Grown From Mononuclear Cells Derived From Neonatal Cord Blood

\begin{tabular}{clcc}
\hline & & \multicolumn{2}{c}{ Percentage of Positive Cells } \\
\cline { 3 - 4 } Cell Surface Marker & & $\begin{array}{c}\text { 9-Day } \\
\text { Culture }\end{array}$ & $\begin{array}{c}\text { 15-Day } \\
\text { Culture }\end{array}$ \\
\hline (Erythroid) blasts & & & \\
CD71 & Transferrin receptor & 95 & 80 \\
CD117 & C-KIT & 80 & 50 \\
Erythroid & & & \\
CD36/GPA & gp IV/glycophorin A & 20 & 21 \\
Nonerythroid & Aminopeptidase N & 5 & $<1$ \\
CD13 & LPS receptor & 5 & $<1$ \\
CD14 & Fc?-receptor & 3 & $<1$ \\
CD89 & Monocyte marker & & 7 \\
CD33 & T-cell receptor & & $<0.1$ \\
CD3 & B4-protein & & $<0.1$ \\
CD19 & C & & \\
\hline
\end{tabular}

All FACS analysis were performed twice on independently derived cultures.

poration of tritiated thymidine) and in a biochemical assay (induction of tyrosine phosphorylation). The cells incorporated tritiated thymidine in response to Epo. SCF and IGF-I did not induce DNA synthesis if added alone, but they enhanced the incorporation of tritiated thymidine when added together with a suboptimal concentration of Epo. The cells did not respond to $\mathrm{TGF} \alpha$ or other epidermal growth factor (EGF)-like ligands, IL-3 or GM-CSF (data not shown). The erythroid proliferation factors Epo, SCF, and IGF-I induced tyrosine phosphorylation of multiple substrate proteins, as detected with antiphosphotyrosine antibodies in a Western blot (Fig 2). No phosphorylation of substrates was detected when cells were stimulated with IL-3, GM-CSF, or EGF-like substrates (Fig 2 and data not shown).

In conclusion, cultures established from bone marrow or cord blood in the presence of Epo, SCF, and Dex consisted of $90 \%$ to $95 \%$ erythroid progenitors. In the following, we used these cultures to determine how corticosteroids contribute to the in vitro expansion of erythroid progenitors.

Human erythroid progenitors require glucocorticosteroids for sustained proliferation. In all avian erythroid progenitors, the GR ligand Dex was indispensable for progenitor selfrenewal. ${ }^{7,26}$ However, the major role of Dex in the outgrowth of erythroid progenitors from human bone marrow mononuclear cells could still be mediated by nonerythroid accessory cells. Human bone marrow cells were grown in Epo, SCF, and either Dex or the GR-antagonist ZK. Amplification of erythroid progenitors from bone marrow cells of several independent donors was at least 10-fold reduced after culture for 10 days in the presence of $\mathrm{ZK}$ as compared with cultures supplemented with Dex (Fig 3A and data not shown). Addition of the GR-antagonist ZK was required to unveil the effect of Dex, due

Table 2. Colonies Derived From 13- or 16-Day Cultures of Neonatal Cord Blood

\begin{tabular}{cccc}
\hline & \multicolumn{3}{c}{ Colony Type Per 105 Cells Seeded } \\
\cline { 2 - 4 } & BFU-E & $\begin{array}{c}\text { Erythroid/ } \\
\text { Myeloid Mixed }\end{array}$ & CFU-GM \\
\hline 13-day culture & 5,750 & 400 & 200 \\
15-day culture & 2,500 & 105 & 100 \\
\hline
\end{tabular}

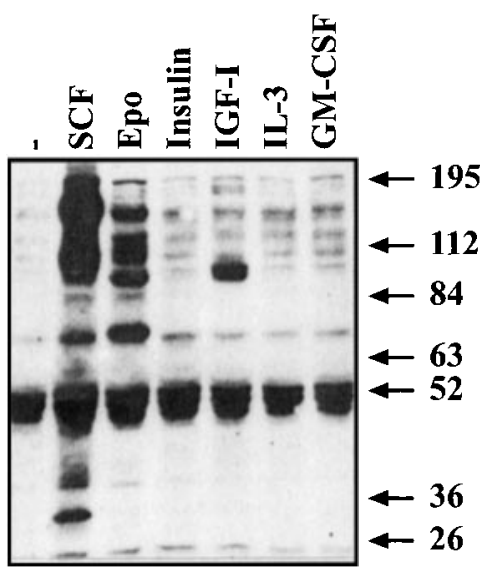

Fig 2. Tyrosine phosphorylation induced by activation of receptors for growth factors and cytokines. Erythroid progenitors were withdrawn from growth factors ovemight and subsequently stimulated for $\mathbf{1 0}$ minutes with the cytokines indicated, using 10-fold higher concentrations than used in liquid cultures. Cell lysates were separated on acrylamide gels and subjected to Westem blot analysis using the antiphosphotyrosine antibody 4G10. Arrows indicate the position of the size markers used.

to the presence of corticosteroids in serum. In the absence of Dex or ZK, the proliferation of erythroid progenitors depends very much on the serum batch used. Previously, we showed that corticosteroids, as a major factor required for the proliferation of avian erythroid progenitors, are removed from serum by freon/charcoal treatment. The addition of ZK112,993 to serum had the same effect. ${ }^{7}$

Subsequently, the colony-forming capacity of aliquots from the same cultures was determined at successive intervals, using a limiting dilution approach. Bone marrow cells were seeded in fibrinogen clots at 2, 5, and 15 cells per well in 96-well plates. The cells, grown in liquid cultures in the presence of either Dex or ZK, were exposed to Epo, IGF-I, and SCF and from each culture again to Dex and ZK. Benzidine-positive colonies were scored after 10 days as small (4 to 30), medium (30 to 100), or large ( $>100$ cells). At the start of the culture (day 0$)$, a similar number of colonies was obtained $(\sim 1.5 \%)$ in the presence of either Dex or ZK. However, in the presence of ZK, the colonies were smaller and more hemoglobinized (Fig 3B).

In liquid cultures containing Dex, the number of erythroid colony-forming units (ECFU) had increased 20-fold in 4 days and 100 -fold in 8 days, with $50 \%$ of these ECFU able to undergo at least another 5 cell divisions (colony size, $>30$ cells). In contrast, bone marrow cultures in presence of the GR-antagonist ZK resulted only in a 10-fold increase of ECFC after 4 days and no further amplification at 8 days of culture (Fig 3B). Irrespective of the conditions of liquid culture, fibrinogen clots containing Dex yielded colonies that were larger and less hemoglobinized and that exceeded 4 to 5 times in colony number compared with fibrinogen clots containing ZK (Fig 3B). The number of colonies per 100 cells seeded was constant under all conditions, regardless of whether 15,5 , or 2 cells had been seeded per well (data not shown).

These data are consistent with the notion that Dex supports sustained proliferation of erythroid progenitors and that it acts 

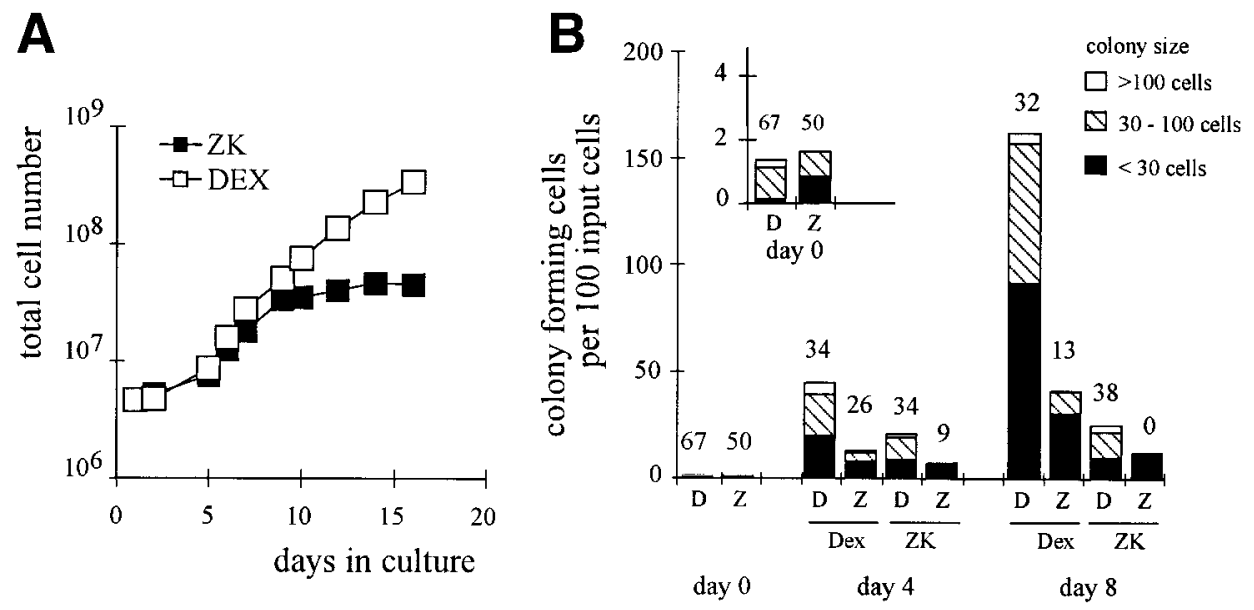

Fig 3. Dex enhances proliferation and colony-forming ability of enythroid progenitors. (A) Human bone marrow cells were cultured in medium complemented with Epo, SCF, IGF-1, and either Dex or ZK ( $\square$ and $\square$, respectively). (B) At days 0, 4, and 8, cell aliquots of both cultures were seeded in fibrinogen clots with 2, 5, and 15 cells per well and medium complemented with Epo, SCF, IGF-1, and either Dex or ZK (indicated by D or $\mathrm{Z}$ at the $\mathrm{X}$-axis) was added. Previous liquid culture conditions are indicated below by Dex or ZK. After 10 days, colonies were stained with benzidine and counted, and the cell number per colony was estimated as small ( 0 to 30 cells), medium ( 30 to 100 cells), or large (>100 cells). Colony number is given per 100 bone marrow cells seeded in the culture at day 0 . The number above the bars indicates the percentage of only partially hemoglobinized colonies.

directly on these progenitors. Dex increased both the number of colony-forming cells in the mass cultures and the proportion of immature colonies derived from these colony-forming cells. The ability to form medium-sized to large colonies in Dex did not change largely in the Dex-treated mass cultures, but rapidly decreased in the presence of $\mathrm{ZK}$.

Cooperation of the GR with the EpoR and c-Kit arrests human proerythroblast differentiation and maintains the expression of immature erythroblast markers. We next tested in more detail how Dex affects the balance of proliferation and differentiation in an established culture of erythroid progenitors. Aliquots from a 6-day-old culture of erythroid progenitors were seeded in media containing Epo, IGF-I, SCF, and either Dex or the GR-antagonist ZK. Cell numbers were counted daily and aliquots were processed to determine hemoglobin content and morphology. Three days after applying the different conditions (Fig 4A), cultures containing ZK became stationary, whereas cultures containing Dex continued to proliferate. Concurrently, hemoglobin levels increased considerably in cells grown in ZK-containing medium (Fig 4B). Cytospins showed that cultures exposed to ZK differentiated completely into small, partially enucleated erythrocyte-like cells and then disintegrated (Fig 4C, bottom panels). In contrast, cultures kept in Dex retained their low hemoglobin content, large size, and basophilic erythroblast morphology throughout the experiment (Fig 4C, top panels). In the absence of Epo, the cells neither proliferated nor differentiated irrespective of the presence of Dex, ZK, or SCF, whereas the presence of Epo but not SCF resulted in rapid differentiation, as shown elsewhere for human cells ${ }^{27}$ as well as for avian progenitors. ${ }^{26}$ The presence of Dex or ZK did not affect Epo-induced differentiation (data not shown), which is in agreement with observations in avian cells in which Dex cooperates with SCF to retain erythroid cells in an immature state. ${ }^{7}$

Earlier work in the chicken had shown that Dex maintained the expression of c-myb, which is a requirement for long-term proliferation. ${ }^{7}$ Self-renewing avian erythroblasts also express c-Kit. Upon induction of differentiation, c-myb and c-Kit are rapidly downregulated. RBTN2 is a transcription factor selectively expressed in immature erythroid cells (M.v.L., unpublished data), which is required for progression past the proerythroblast stage according to observations in RBTN2 $-/-$ mice. ${ }^{28}$ In contrast, expression of GATA-1 is required during terminal differentiation..$^{29,30}$ We examined whether Dex affects transcription of c-myb, c-Kit, RBTN2, and GATA-1 in human erythroid progenitors. Aliquots from a 10-day-old culture were kept for 48 hours in medium containing charcoal-stripped serum and growth factors, but no steroid hormones. Subsequently, the GR agonist Dex or antagonist ZK were added, and cell samples were processed daily for Northern blot analysis. mRNA levels of c-myb, c-Kit, and RBTN2 increased in the presence of Dex, whereas they remained low or declined in ZK (Fig 5). In contrast, expression levels of GATA-1 were not affected by activation or inactivation of the GR. The apparent upregulation of c-myb, c-Kit, and RBTN2 is consistent with the finding that Dex stimulates sustained proliferation of immature erythroid cells and delays differentiation.

Origin of erythroid progenitors capable of sustained cell proliferation. We then set out to characterize the progenitor cell phenotype that was responsive to stimulation of expansion by Epo, SCF, and Dex. Human bone marrow cells were separated into $\mathrm{CD}_{4} 4^{+}$and $\mathrm{CD}_{4} 4^{-}$fractions. The $\mathrm{CD} 34^{-}$ fraction was subjected twice to depletion of $\mathrm{CD} 34^{+}$cells and finally contained less than $0.1 \% \mathrm{CD}^{+}{ }^{+}$cells by FACS analysis (Fig 6A). The CD34+ cells were stained for CD34, CD71, and CD38 and were sorted by FACS into two subfractions: a blast fraction (CD34 ${ }^{+}$, low CD71, low CD38; gate R3, Fig 6C) and a BFU-E-enriched fraction $\left(\mathrm{CD} 34^{+}\right.$, high CD71; gate R4, Fig 6C).

After purification, the three subpopulations (blast cells, BFU-E fraction, and $\mathrm{CD} 34^{-}$cells) were seeded in medium containing Epo, SCF, and Dex, and proliferation was monitored 
A

Proliferation

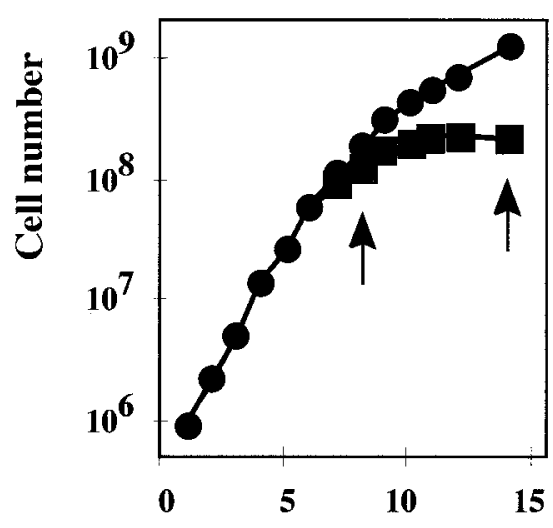

days in culture
B

\section{Differentiation}

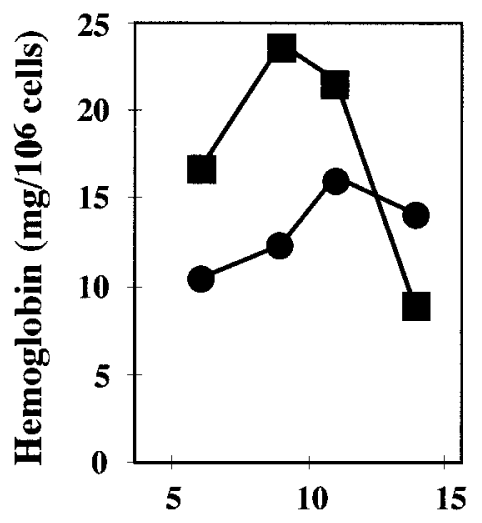

days in culture

Dexamethasone

ZK 112,993

C

Fig 4. Dex supports proliferation and inhibits differentiation. Cells from a culture of neonatal cord blood cells were washed 5 days after seeding and aliquots exposed to medium plus Epo, SCF, and Dex (O) or Epo, SCF, and the GR-antagonist ZK 112,993 (ם). (A) Proliferation was monitored by calculating cumulative cell numbers. (B) Hemoglobin accumulation was determined at the days indicated and plotted as milligrams of hemoglobin per $10^{6}$ cells. (C) At the days indicated by arrows in (A), cell samples from cultures containing Dex (upper panels) or ZK 112,993 (lower panels) were cytocentrifuged onto slides and stained cytochemically with a specific stain for hemoglobin. Well-hemoglobinized cells show a dark to black cytoplasm.
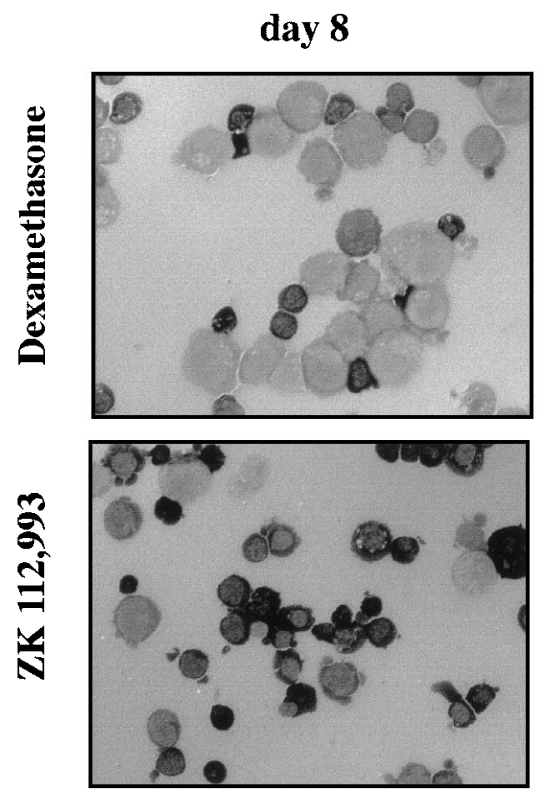

day 14
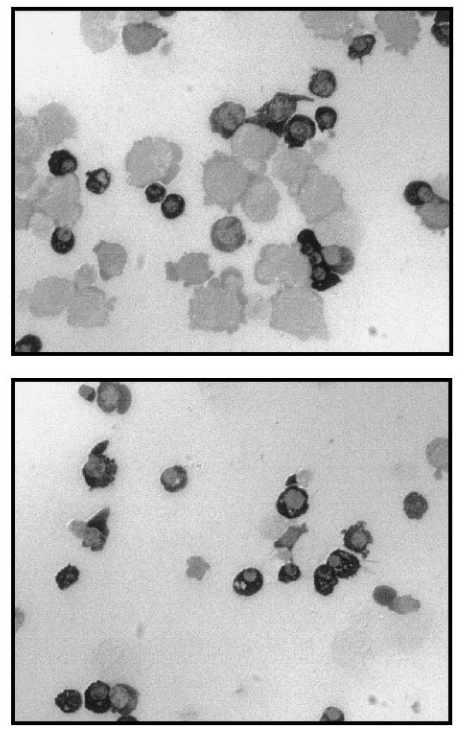

by daily counting (Fig 6D). Approximately equal numbers of erythroid progenitors could be grown from all three cell populations, which corresponded with an expansion of $10^{5}$-fold for the purified BFU-E fraction (Fig 6D).

In all cultures, the increase in cell numbers reached a plateau at approximately 15 days when the cells started to mature to hemoglobinized cells. All cultures contained greater than $90 \%$ erythroid progenitors, as shown by cytocentrifugation and benzidine staining (data not shown). These results demonstrate that cultures of committed erythroid progenitors can be established from cells of varying maturity (including CD34- erythroid progenitors, generally considered as [post-]CFU-E) in the presence of Epo, SCF, and glucocorticoids.

\section{DISCUSSION}

In this report, we demonstrate that sustained proliferation of human erythroid progenitors can be induced upon activation of EpoR, c-Kit, and GR by their respective ligands. Mass cultures yielding $10^{9}$ to $10^{11}$ erythroid cells were established from a few million mononuclear cells derived from umbilical cord blood, bone marrow, or peripheral blood. The cultures differed from previously described cultures of erythroid progenitors by their dependence on GR-ligands. These ligands were shown to exert their effect directly on the erythroid progenitors, and they maintained the colony-forming ability of the progenitors expanded in liquid culture while suppressing their differentiation. The cultures consisted of greater than $90 \%$ pure erythroid 


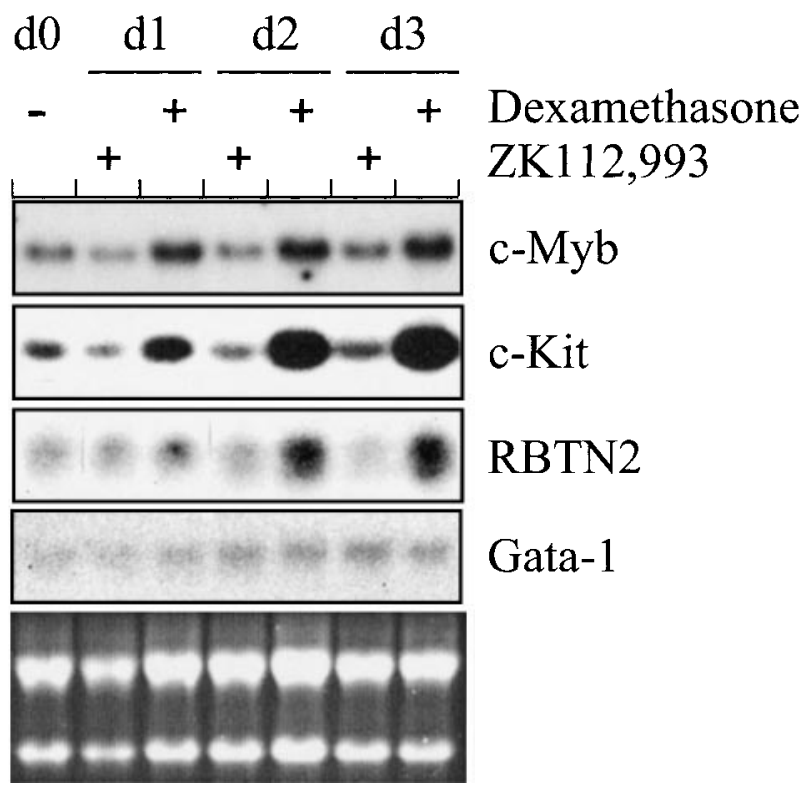

Fig 5. Dex maintains high expression levels of c-myb, c-Kit, and RBTN2. A culture of erythroid progenitor cells was kept for $\mathbf{2}$ days in medium containing Epo, SCF, IGF-I, and freon/charcoal stripped serum (depleted from Dex). Thereafter, aliquots of the culture were cultivated in the same medium supplemented with either Dex or ZK 112,993 at $10^{-6} \mathrm{~mol} / \mathrm{L}$. Total RNA was extracted from untreated cells (day $\mathbf{0}$ ) or from cells cultured for 1, 2, or 3 days in GR agonist or antagonist. Total RNA was analyzed on Northem blots, using fulllength c-DNA probes of c-myb, c-Kit, RBTN2, and GATA-1. The ethidium staining is shown in the bottom panel as a loading control.

progenitors, apparent mainly as proerythroblasts and basophilic erythroblasts and able to undergo approximately 15 to 20 generations in culture. These cultures of proliferating human erythroblasts could be obtained from both $\mathrm{CD} 34^{+}$and $\mathrm{CD} 34^{-}$ cells as well as from a cell fraction enriched for BFU-E. This suggests that the expansion capacity of human erythroid progenitors, like their counterparts in chicken and mouse, may be greater than hitherto anticipated and that glucocorticoids play an important role in the regulation of the proliferation/ differentiation program.

A recent report described a similar approach to grow and differentiate primary human erythroblasts. ${ }^{27,31}$ In this report, the differentiation characteristics of these cells were characterized in more detail.

In avian erythroblastosis virus (AEV)-transformed cells, a mutated epidermal growth factor receptor ( $\mathrm{v}$-ErbB) cooperates with a mutated nuclear receptor for thyroid hormone (v-ErbA), which results in self-renewal of erythroid progenitors for the entire in vitro life-span of a chicken cell ${ }^{32,33}$ (25 to 40 generations). Subsequently, normal erythroid progenitors (SCF/ TGF $\alpha$ progenitors) could be identified that express nonmutated members of receptor tyrosine kinases and nuclear hormone receptors and can be induced to self-renewal in the presence of human recombinant TGF $\alpha$ as a ligand for c-ErbB, avian SCF, and both Dex and estradiol as steroid ligands. Ligand activation of both the steroid hormone receptors and the tyrosine kinases was essential for self-renewal of these cells. ${ }^{4-7,14}$ These progenitors are relatively rare, being present at frequencies of only 1 in
$15,000 .{ }^{6}$ Recently, a more abundant avian erythroid progenitor was identified (EpoR-progenitors, occurring at a frequency of 1 in $400^{26}$ ), which is dependent on the presence of Epo, SCF, and Dex for self-renewal. 26,34 The life span of these EpoRprogenitors was shorter than that of SCF/TGF $\alpha$ progenitors (15 to 20 generations). These avian progenitors closely correspond to those obtained in the cultures of human erythroblasts. They do not respond to EGF-like ligands or estradiol and terminally differentiate upon culture progression rather than entering senescence as undifferentiated cells typical of the SCF/TGF $\alpha$ progenitors.

Differentiation of avian erythroid progenitors can be induced at any time by removal of the self-renewal factors (TGF $\alpha, \mathrm{E} 2$, and Dex or Epo, SCF, and Dex, respectively) and addition of differentiation factors (Epo plus insulin). Upon differentiation induction, the cells undergo a fixed number of 5 cell divisions, during which cell cycle and cell size control is profoundly altered. ${ }^{35}$ The human progenitors grown from bone marrow or cord blood could be similarly induced to differentiate into enucleated red blood cells, when the proliferation factors Epo, $\mathrm{SCF}$, and Dex were replaced by the differentiation factors Epo and insulin. The cells underwent a limited number of divisions, became rapidly smaller (from $900 \mathrm{fL}$ in the progenitors to $\sim 250$ $\mathrm{fL}$ in the mature cells), and accumulated hemoglobin levels comparable to peripheral blood erythrocytes (mean cellular hemoglobin content of 35 to $40 \mathrm{~g} / \mathrm{dL}$; M.v.L., unpublished data). Taken together, these data strongly suggest that control of erythroid proliferation and differentiation is comparable in mammalian and avian progenitors. It is therefore likely that previously described mechanisms regulating the balance of self-renewal versus terminal differentiation in avian cells similarly control the balance between proliferation and differentiation in mammalian cells. $3,25,33,36$

Cultures of human erythroid progenitors could be established both from $\mathrm{CD}_{3} 4^{-}$and $\mathrm{CD} 34^{+}$cells, predominantly containing cells with the morphology of proerythroblasts. Cultures initiated from $\mathrm{CD} 34^{+}$cells only contained $\mathrm{CD} 34^{-}$cells by day 5 . Cells with such a phenotype are generally considered to be (post-)CFU-E. However, a CFU-E is characterized by a very limited proliferation capacity (3 to 5 cell divisions). Even BFU-E are reported to undergo a maximum of 10 cell divisions, ${ }^{37}$ less than the 20 cell divisions induced by the cooperation of cytokines and steroid hormones that we observed in our cultures. This indicates that committed erythroid progenitors have a larger expansion capacity than hitherto anticipated.

Glucocorticoids have pleiotropic effects on hematopoietic cells: activation of the GR induces apoptosis in lymphoid and myelomonocytic cells, while it protects granulocytes from apoptosis $^{38}$ and stimulates proliferation of erythroid progenitors $^{7}$ (this report). Repression of macrophages and lymphocytes is caused by the ability of the GR to interact with the transcription factors $\mathrm{AP}-1$ and $\mathrm{NF} \mathrm{B}$, independent of DNA binding by the GR, which results in repression of transcription by these complexes. ${ }^{16}$ Several members of the NFKB family are also expressed in erythroid progenitors. ${ }^{39}$ However, repression appears not essential for the function of the GR in erythroid progenitors. Instead, proliferation induction of avian erythroid cells is dependent on intact DNA binding and transcriptional activation domains of the GR. ${ }^{7}$ We recently confirmed this 
A

CD34- $^{-}(2 x)$

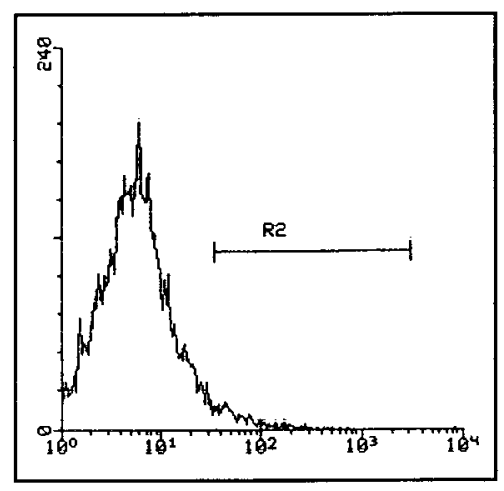

Fig 6. Enythroid progenitors can be grown from $\mathrm{CD}_{34}^{+}$and CD34- cell fractions. Mononuclear bone marrow cells were fractionated into CD34- and CD34+ fractions using Minimacs columns. The CD34- fraction was repurified using the same columns ( $A$ and $B$ ). Cells were stained for CD34 to verify the purity of the CD34- and CD34+ fraction by FACS. The CD34+ cells were costained with CD71 (horizontal axis) and CD38 (vertical axis; C). Only CD34+ cells were gated (A and B; gate R2). Fractions highly enriched for BFU-E (C; R4, high CD71, medium CD38) or immature blast cells (C; R3; medium-low CD71, medium-low CD38) were purified by sorting. CD34- cells ( $\triangle$ ), the sorted BFU-E progenitors $(O)$, and the sorted immature blast cells ( $\square$ ) were cultured in CFU-E medium supplemented with Epo, SCF, IGF-I, and Dex. Cumulative cell numbers were calculated (D).

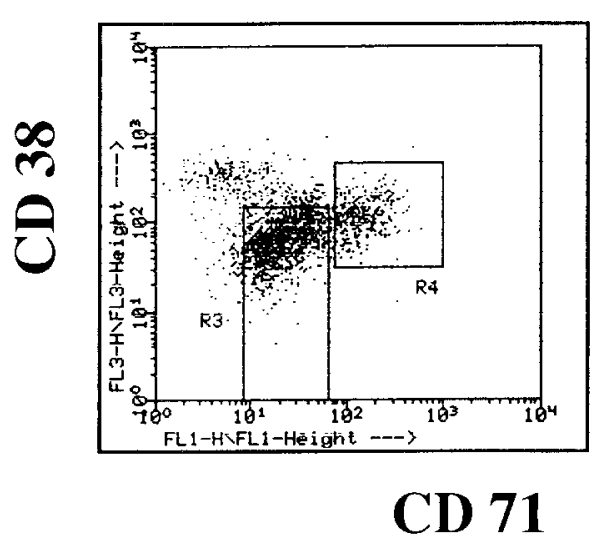

B

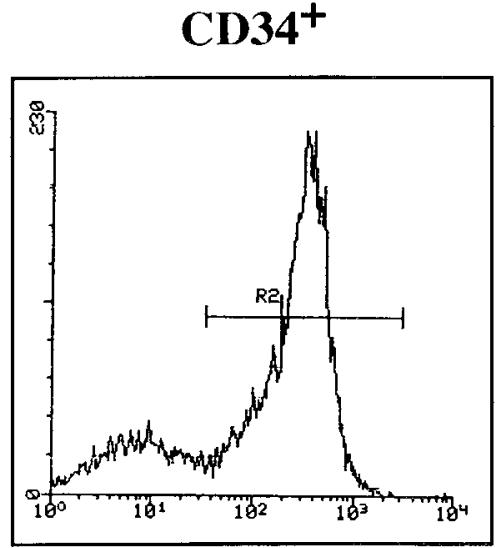

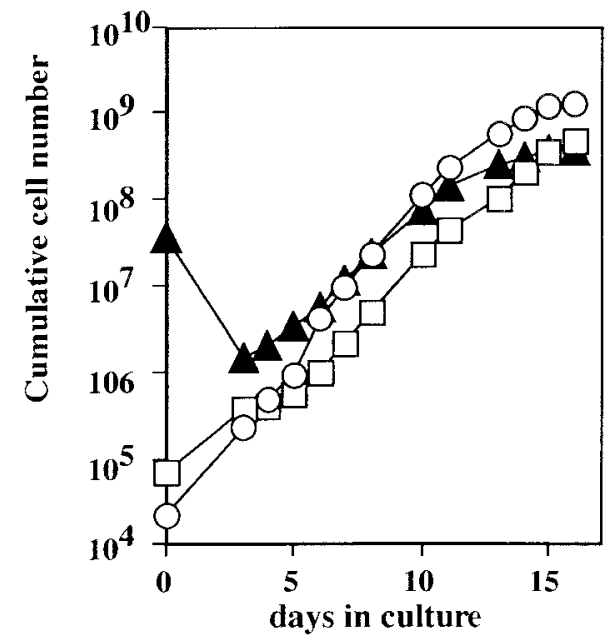

notion in mice carrying a mutated GR, which lacked the ability to transactivate upon hormone binding, but retained transrepressing activity. ${ }^{40}$ Erythroblasts could be grown from fetal livers of wild-type mice using the same conditions described here, but not from fetal livers of the GRdim/dim mice, confirming the crucial role of the GR and its transactivation ability in mammalian erythroblast proliferation.

Although we could not expand erythroblasts from fetal livers of mice deficient for the $\mathrm{GR}^{41}$ or from GRdim/dim mice, ${ }^{40}$ these mice do not show obvious defects in normal in vivo erythropoiesis. Studies addressing stress erythropoiesis in mice showed that upregulation of erythroid progenitors (BFU-E and CFU-E) on anemia induction occurred exclusively in the spleen and required a functional c-Kit receptor tyrosine kinase. ${ }^{42}$ Recently, we have obtained evidence that this upregulation of spleen erythroid progenitors in anemic mice does not occur in the GR dim/dim mice (A. Bauer and H.B., manuscript in preparation). Because glucocorticoids are highly upregulated on blood loss or injury, the GR may play a physiological role in stress erythropoiesis.

The GR has been shown to interact with STAT5, resulting in enhanced transcription of $\beta$-casein. ${ }^{43}$ Although disputed, DNA binding by the GR appears important for its synergistic action with STAT5. ${ }^{4-46}$ This synergy has so far only been described for the $\beta$-casein promoter. We tested expression of the STAT5 target gene $\mathrm{CIS}^{47}$ in primary erythroid progenitors stimulated with or without Epo in the presence of either Dex or the GR-antagonist ZK. Cis expression was fully dependent on Epo-induced STAT5-phosphorylation, but independent of GR activation. Thus, we could not demonstrate synergy between STAT5 and the GR in erythroid progenitors. However, we cannot exclude that this mechanism plays a role in the activation of other target genes.

Among several genes tested that are critical for erythroid self-renewal, the GR induced expression of c-myb. Notably, constitutive expression of activated Myb (v-Myb) abrogated the requirement for corticosteroids. ${ }^{7}$ Mice deficient in Myb die at day 15 of gestation when they are severely anemic. ${ }^{48}$ One of the genes regulated by c-Myb is c-Kit. ${ }^{49,50}$ In the cultured erythroid progenitors, activation of the GR enhanced expression of 
c-myb, c-Kit, and the erythroid transcription factor RBTN2. One mechanism by which corticosteroids cooperate with SCF and Epo may involve maintenance of c-Kit expression. SCF is required to delay differentiation of erythroid progenitors. ${ }^{15}$ The EpoR appears to form a complex with c-Kit, ${ }^{51}$ and crossphosphorylation of the receptors has been reported. ${ }^{52-54}$ Constitutive overexpression of c-Kit in the absence of corticosteroids delays differentiation, but it is not sufficient to induce selfrenewal of avian erythroid progenitors. ${ }^{14}$ Thus, maintaining c-Kit expression is an important contribution of the GR to sustained proliferation, but induction of renewal divisions most likely involves additional genes controlled by the GR via c-Myb and could involve transcription factors such as RBTN2.

\section{ACKNOWLEDGMENT}

The authors thank Dr B. Royer-Pokora for the gift of the TTG2/ RBTN2 probe, Eva Deiner and Petra Buchinger for expert technical assistance, Saskia Buchwald and Dr B. Wognum for help and advice in FACS-sorting of cells, and Drs I.P Touw and T. van Dijk for critical reading of the manuscript.

\section{REFERENCES}

1. Alter BP: Biology of erythropoiesis. Ann NY Acad Sci 731:36, 1994

2. Keller G: Hematopoietic stem cells. Curr Opin Immunol 4:133, 1992

3. Beug H, Bauer A, Dolznig H, von Lindern M, Lobmayer L, Mellitzer G, Steinlein P, Wessely O, Mullner E: Avian erythropoiesis and erythroleukemia: Towards understanding the role of the biomolecules involved. Biochim Biophys Acta 1288:M35, 1996

4. Pain B, Woods CM, Saez J, Flickinger T, Raines M, Peyrol S, Moscovici C, Moscovici MG, Kung HJ, Jurdic P, Samarut J: EGF-R as a hemopoietic growth factor receptor: The c-erbB product is present in chicken erythrocytic progenitors and controls their self-renewal. Cell 65:37, 1991

5. Schroeder C, Gibson L, Nordstrom C, Beug H: The estrogen receptor cooperates with the TGF alpha receptor (c-erbB) in regulation of chicken erythroid progenitor self-renewal. EMBO J 12:951, 1993

6. Hayman MJ, Meyer S, Martin F, Steinlein P, Beug H: Self-renewal and differentiation of normal avian erythroid progenitor cells: Regulatory roles of the TGF alpha/c-ErbB and SCF/c-kit receptors. Cell 74:157, 1993

7. Wessely O, Deiner E, Beug H, von Lindern M: The glucocorticoid receptor is a key regulator of the decision between self renewal and differentiation in erythroid progenitors. EMBO J 16:267, 1997

8. Bauer A, Ulrich E, Andersson M, Beug H, von Lindern M: Mechanism of transformation by v-ErbA: Replacement of steroid hormone receptor function in self renewal induction. Oncogene 15:701, 1997

9. Wu H, Liu X, Jaenisch R, Lodish HF: Generation of committed erythroid BFU-E and CFU-E progenitors does not require erythropoietin or the erythropoietin receptor. Cell 83:59, 1995

10. Lin CS, Lim SK, D'Agati V, Costantini F: Differential effects of an erythropoietin receptor gene disruption on primitive and definitive erythropoiesis. Genes Dev 10:154, 1996

11. Broxmeyer HE, Maze R, Miyazawa K, Carow C, Hendrie PC, Cooper S, Hangoc G, Vadhan-Raj S, Lu L: The kit receptor and its ligand, steel factor, as regulators of hemopoiesis. Cancer Cells 3:480, 1991

12. Williams DE, de Vries P, Namen AE, Widmer MB, Lyman SD: The Steel factor. Dev Biol 151:368, 1992

13. Uoshima N, Ozawa M, Kimura S, Tanaka K, Wada K, Kobayashi Y, Kondo M: Changes in c-Kit expression and effects of SCF during differentiation of human erythroid progenitor cells. Br J Haematol 91:30, 1995

14. Wessely O, Mellitzer G, von Lindern M, Levitzki A, Gazit A, Ischenko I, Hayman MJ, Beug H: Distinct roles of the receptor tyrosine kinases c-ErbB and c-Kit in regulating the balance between erythroid cell proliferation and differentiation. Cell Growth Differ 8:481, 1997

15. Muta K, Krantz SB, Bondurant MC, Dai CH: Stem cell factor retards differentiation of normal human erythroid progenitor cells while stimulating proliferation. Blood 86:572, 1995

16. Beato M, Herrlich P, Schutz G: Steroid hormone receptors: Many actors in search of a plot. Cell 83:851, 1995

17. Golde DW, Bersch N, Cline MJ: Potentiation of erythropoiesis in vitro by dexamethasone. J Clin Invest 57:57, 1976

18. Dainiak N, Hoffman R, Ritchey AK, Floyd V, Callahan M: In vitro steroid sensitivity testing: A possible means to predict response to therapy in primary hypoproliferative anemia. Am J Hematol 9:401, 1980

19. Billat CL, Felix JM, Jacquot RL: In vitro and in vivo regulation of hepatic erythropoiesis by erythropoietin and glucocorticoids in the rat fetus. Exp Hematol 10:133, 1982

20. Amylon MD, Perrine SP, Glader BE: Prednisone stimulation of erythropoiesis in leukemic children during remission. Am J Hematol 23:179, 1986

21. Kowenz E, Leutz A, Doderlein G, Graf T, Beug H: Ts-oncogenetransformed erythroleukemic cells: A novel test system for purifying and characterizing avian erythroid growth factors, in Neth R, Gallo RC, Greaves MF, Kabish H (eds): Modern Trends in Human Leukemia VII. Heidelberg, Germany, Springer-Verlag, 1987, p 199

22. Beug H, Palmieri S, Freudenstein C, Zentgraf H, Graf $\mathrm{T}$ : Hormone-dependent terminal differentiation in vitro of chicken erythroleukemia cells transformed by ts mutants of avian erythroblastosis virus. Cell 28:907, 1982

23. Chomczynski P, Sacchi N: Single-step method of RNA isolation by acid guanidinium thiocyanate-phenol-chloroform extraction. Anal Biochem 162:156, 1987

24. Maniatis T, Fritsch EF, Sambrook J: Molecular Cloning: A Laboratory Manual. Cold Spring Harbor, NY, Cold Spring Harbor Laboratory, 1982

25. Steinlein P, Wessely O, Meyer S, Deiner EM, Hayman MJ, Beug $\mathrm{H}$ : Primary, self-renewing erythroid progenitors develop through activation of both tyrosine kinase and steroid hormone receptors. Curr Biol 5:191, 1995

26. Wessely O, Bauer A, Tran-Quang C, von Lindern M, Deiner EM, Steinlein P, Ghysdael J, Beug H: A novel way to induce erythroid progenitor self renewal: Cooperation of c-Kit with the erythropoietin receptor. Biol Chem 380:187, 1999

27. Panzenbock B, Bartunek P, Mapara MY, Zenke M: Growth and differentiation of human stem cell factor/erythropoietin-dependent erythroid progenitor cells in vitro. Blood 92:3658, 1998

28. Warren AJ, Colledge WH, Carlton MB, Evans MJ, Smith AJ, Rabbitts TH: The oncogenic cystein-rich LIM domain protein rbtn2 is essential for erythroid development. Cell 78:45, 1994

29. Pevny L, Lin CS, D' Agati V, Simon MC, Orkin SH, Costantini F: Development of hematopoietic cells lacking transcription factor GATA-1. Development 121:163, 1995

30. Fujiwara Y, Browne CP, Cunniff K, Goff SC, Orkin SH: Arrested development of embryonic red cell precursors in mouse embryos lacking transcription factor GATA-1. Proc Natl Acad Sci USA 93: 12355, 1996

31. Beug H, Wessely O, von Lindern M: Verfahren zur Herstellung und Züchtung hämatopoetischer Vorläuferzellen, Case 14/025 (extension) $\mathrm{DI} \mathrm{Fa} / \mathrm{rst}$, Boehringer Ingelheim International GMBH, 55216 Ingelheim am Rhein, BRD, 1996

32. Hayman MJ, Beug H: Avian erythroblastosis: A model system to study oncogene co-operation in leukemia. Cancer Surv 15:53, 1992 
33. Beug H, Mullner EW, Hayman MJ: Insights into erythroid differentiation obtained from studies on avian erythroblastosis virus. Curr Opin Cell Biol 6:816, 1994

34. Bauer A, Mikulits W, Lagger G, Stengl G, Brosch G, Beug H: The thyroid hormone receptor functions as a ligand-operated, developmental switch between proliferation and differentiation of erythroid progenitors. EMBO J 17:4291, 1998

35. Dolznig H, Bartunek P, Nasmyth K, Mullner EW, Beug H: Terminal differentiation of normal chicken erythroid progenitors: Shortening of G1 correlates with loss of D-cyclin/cdk4 expression and altered cell size control. Cell Growth Differ 6:1341, 1995

36. Müllner EW, Dolznig H, Beug H: Cell cycle regulation and erythroid differentiation, in Vainio O, Imhof BA (eds): Immunology and Developmental Biology of the Chicken. Current Topics in Microbiology and Immunology. New York, NY, Springer Verlag, 1996, p 171

37. Marley SB, Amos TAS, Gordon MY: Kinetics of colony formation by BFU-E grown under different culture conditions in vitro. Br J Haematol 92:559, 1996

38. Liles WC, Dale DC, Klebanoff SJ: Glucocorticoids inhibit apoptosis of human neutrophils. Blood 86:3181, 1995

39. Zhang MY, Sun SC, Bell L, Miller BA: NF-kappaB transcription factors are involved in normal erythropoiesis. Blood 91:4136, 1998

40. Reichardt HM, Kaestner KH, Tuckermann J, Kretz O, Wessely O, Bock R, Gass P, Schmid W, Herrlich P, Angel P, Schutz G: DNA binding of the glucocorticoid receptor is not essential for survival. Cell 93:531, 1998

41. Cole PJ, Blendy JA, Monaghan AP, Kriegelstein K, Schmid W, Aguzzi A, Fantuzzi G, Hummler E, Unsicker K, Schütz G: Targeted disruption of the glucocorticoid receptor gene blocks adrenergic chromaffin cell development and severely retards lung maturation. Genes Dev 9:1608, 1995

42. Broudy VC, Lin NL, Priestley GV, Nocka K, Wolf NS: Interaction of stem cell factor and its receptor c-kit mediates lodgment and acute expansion of hematopoietic cells in the murine spleen. Blood $88: 75,1996$

43. Stocklin E, Wissler M, Gouilleux F, Groner B: Functional interactions between Stat5 and the glucocorticoid receptor. Nature 383:726, 1996

44. Cella N, Groner B, Hynes NE: Characterization of Stat5a and
Stat5b homodimers and heterodimers and their association with the glucocortiocoid receptor in mammary cells. Mol Cell Biol 18:1783, 1998

45. Lechner J, Welte T, Doppler W: Mechanism of interaction between the glucocorticoid receptor and Stat5: Role of DNA-binding. Immunobiology 198:112, 1997

46. Stoecklin E, Wissler M, Moriggl R, Groner B: Specific DNA binding of Stat5, but not of glucocorticoid receptor, is required for their functional cooperation in the regulation of gene transcription. Mol Cell Biol 17:6708, 1997

47. Yoshimura A, Ohkubo T, Kiguchi T, Jenkins NA, Gilbert DJ, Copeland NG, Hara T, Miyajima A: A novel cytokine-inducible gene CIS encodes an SH2-containing protein that binds to tyrosinephosphorylated interleukin 3 and erythropoietin receptors. EMBO J 14:2816, 1995

48. Mucenski ML, McLain K, Kier AB, Swerdlow SH, Schreiner CM, Miller TA, Pietryga DW, Scott WJ Jr, Potter SS: A functional c-myb gene is required for normal murine fetal hepatic hematopoiesis. Cell 65:677, 1991

49. Ratajczak MZ, Perrotti D, Melotti P, Powzaniuk M, Calabretta B, Onodera K, Kregenow DA, Machalinski B, Gewirtz AM: Myb and ets proteins are candidate regulators of c-kit expression in human hematopoietic cells. Blood 91:1934, 1998

50. Vandenbark GR, Chen Y, Friday E, Pavlik K, Anthony B, deCastro C, Kaufman RE: Complex regulation of human c-kit transcription by promoter repressors, activators, and specific myb elements. Cell Growth Differ 7:1383, 1996

51. Broudy VC, Lin NL, Buhring HJ, Komatsu N, Kavanagh TJ: Analysis of c-kit receptor dimerization by fluorescence resonance energy transfer. Blood 91:898, 1998

52. Wu H, Klingmuller U, Besmer P, Lodish HF: Interaction of the erythropoietin and stem-cell-factor receptors. Nature 377:242, 1995

53. Wu H, Klingmuller U, Acurio A, Hsiao JG, Lodish HF: Functional interaction of erythropoietin and stem cell factor receptors is essential for erythroid colony formation. Proc Natl Acad Sci USA 94:1806, 1997

54. Jacobs-Helber SM, Penta K, Sun Z, Lawson A, Sawyer ST: Distinct signaling from stem cell factor and erythropoietin in HCD57 cells. J Biol Chem 272:6850, 1997 